\title{
Degradation and sorption of the herbicides 2,4-D and quizalofop-P-ethyl and their metabolites in soils from railway tracks
}

\author{
Ignaz J. Buerge * (1), Pavlina Pavlova, Irene Hanke, Astrid Bächli and Thomas Poiger(1)
}

\begin{abstract}
Background: Broad spectrum of activity and low potential for leaching to groundwater are important arguments for the application of the herbicide glyphosate on railway tracks. Nevertheless, certain weeds are insufficiently controlled or develop resistance, and there is also an ongoing controversial discussion about possible carcinogenicity of glyphosate. Alternatives are thus strongly desired. 2,4-D and quizalofop-P-ethyl (QE) are two selective herbicides with a complementary spectrum of activity. When used in agriculture, the compounds and their metabolites exhibit low groundwater contamination potential. Uses on railway tracks may, however, be more critical, since degradation likely is slower and mobility higher than in agricultural soils. In this study, we investigated degradation and sorption of the two active substances as well as five metabolites in three soils collected from railway tracks and in a crushed sand, used for construction works.

Results: In these railway materials, the compounds were indeed degraded slower than in agricultural soils (mean half-lives differed by a factor of 1.4-26, depending on the substance) and mobility was higher (mean sorption coefficients differed by a factor of 3-19). Half-lives and sorption coefficients were also estimated by extrapolation of data from agricultural soils, considering the organic carbon content of railway soils and agricultural soils. Estimated values were more conservative than measured values.

Conclusions: Based on our experimental data, possible leaching to groundwater is predicted to be highest for 2,4-D and quizalofop-acid, the primary metabolite of QE, moderate for 2,4-dichlorophenol, the primary metabolite of 2,4-D, but low for QE. Secondary and tertiary metabolites were formed in only low quantities. For herbicides, for which no measured parameters are available for railway soils, estimated values may also be a viable alternative for a first tier groundwater assessment.
\end{abstract}

Keywords: Selective herbicides, Weed control on railways, Glyphosate alternatives, Groundwater contamination, Comparison with agricultural soils

\section{Background}

In many countries, weed control on railway tracks relies on glyphosate [1-4]. Glyphosate is a broad-spectrum herbicide with systemic properties [5] and, therefore, shows good activity not only against annual, but also most perennial weeds, including weeds with deep roots that are

*Correspondence: ignaz.buerge@agroscope.admin.ch

Agroscope, Plant Protection Chemistry, 8820 Wädenswil, Switzerland commonly present on railway tracks. A further advantage is that glyphosate and also its metabolite AMPA exhibit low potential for leaching to groundwater [6-8].

Despite these advantages, weed control on railway tracks should not depend on glyphosate alone. Some weeds are not sufficiently controlled, for example, horsetails (Equisetum) with their acicular stems and extensive rhizomes [2, 9]. Long-term use of glyphosate may also promote development of resistance [4, 5]. Moreover, there is an ongoing, controversial discussion about 
possible carcinogenicity of glyphosate [10-12]. Alternatives are thus strongly desired, along with herbicides that complement the activity of glyphosate on railway tracks.

However, active substances with a wide spectrum of activity comparable to glyphosate are rare. In Europe, for example, the broad-spectrum herbicides paraquat or imazapyr are not registered and approval of diquat, glufosinate, or amitrole has not been extended. Therefore, selective herbicides need to be considered for use on railway tracks, although in this case, for sufficient weed control, two or more active substances with a complementary activity are required.

Auxine-type herbicides and ACCase-inhibitors are two prominent groups of selective herbicides. For this study, we selected one compound of each group. The auxin-type herbicide 2,4-D acts against most annual and perennial broad-leaved weeds with some activity against sedges and rushes $[13,14]$. In particular, it shows activity against horsetails $[15,16]$. The second compound, quizalofopP-ethyl, is an ACCase-inhibitor and has a rather narrow spectrum of activity against grasses of the Poaceae family [17]. Altogether, the two compounds complement each other reasonably well. The compounds are systemic in plants and they are applied after emergence of weeds, i.e., they allow for treatment of single plants and do not need to be applied on the whole surface of railway tracks.

In addition to the spectrum of activity, groundwater protection is of particular importance when evaluating herbicides for use on railway tracks. The tracks are designed to efficiently drain rainwater. This ensures their stability and avoids deformation due to freezing water. Soils below the railway ballast usually have low organic carbon contents, which results in weak sorption of most organic compounds. A few decades ago, atrazine and diuron were widely used for weed control on railway tracks, and in several cases, contamination of aquifers with these compounds or their metabolites was linked to uses on railways $[1,18]$. Glyphosate and AMPA, however, are strongly retained by mineral substrates such as iron oxides and are thus less susceptible to leaching [6, $19,20]$. To avoid the risk of groundwater contamination, potential glyphosate alternatives must exhibit sufficient sorption and/or fast degradation in soils below the railway ballast.

Based on data for agricultural topsoils, it can be concluded that 2,4-D and quizalofop-P-ethyl pose low risk of groundwater contamination [13, 17, 21]. However, topsoils are normally removed when constructing railway tracks and for the remaining subsoils, these basic environmental parameters are often not available.

The aim of the present study was, therefore, to determine sorption and degradation rate coefficients for 2,4-D and quizalofop-P-ethyl in a number of railway soils, selected to represent a realistic worst-case regarding both properties. In soils, 2,4-D is transformed to 2,4-dichlorophenol and 2,4-dichloroanisole (Fig. 1) [13]. Quizalofop-P-ethyl is rapidly cleaved to quizalofop-P-acid that is further transformed to two hydroxylated metabolites, 3-OH-quizalofop-acid and 3-OH-CQO (Fig. 1) [17]. Sorption and degradation studies were thus also performed with these 5 metabolites. Finally, we investigated whether such substance properties for railway soils may also be estimated from data for agricultural soils.

\section{Materials and methods Chemicals}

2,4-D ((2,4-dichlorophenoxy)acetic acid, purity, 98\%) was from Thermo Fisher (Karlsruhe, Germany), 2,4-DCP (2,4-dichlorophenol, 99\%), quizalofop-P-ethyl (98.4\%), quizalofop-P-acid (97.8\%), and 2,3-dihydroxy-quinoxaline (98\%, used as internal standard for 3-OH-CQO) from Sigma-Aldrich (Steinheim, Germany), 2,4-DCA (2,4-dichloroanisole, 99.5\%) from Dr. Ehrenstorfer (Augsburg, Germany), the internal standards 2,4-D-D $\mathrm{D}_{3}(98 \%)$ and 2,4-DCP-D ${ }_{3}$ (98\%) from Cambridge Isotope Laboratories (Tewksbury, MA, labelled in the phenyl-ring), and quizalofop-ethyl- $\mathrm{D}_{3}(99.9 \%)$ from CDN Isotopes (PointeClaire, Canada, labelled in the methyl-group). 3-OH-quizalofop-acid $(\approx 96.0 \%)$ and $3-\mathrm{OH}-\mathrm{CQO}(\approx 98.2 \%)$ were kindly provided by Nissan Chemical Industries (Tokyo, Japan).

The internal standard 2,4-DCA-D 3 was prepared by methylation of 2,4-DCP- $\mathrm{D}_{3}$ using diazomethane [22]. Quizalofop-acid- $D_{3}$ was prepared from quizalofop-ethyl$\mathrm{D}_{3}$ by alkaline hydrolysis. For that, $2.5 \mathrm{mg}$ of quizalofopethyl- $\mathrm{D}_{3}$ was dissolved in $0.5 \mathrm{~mL}$ methanol and diluted with $10 \mathrm{~mL}$ of a sodium hydroxide solution $(0.01 \mathrm{M})$. After $4 \mathrm{~h}$, the solution was acidified with sulfuric acid to $\mathrm{pH} \approx 2$ (note that the hydrolysis product quizalofop-acid$\mathrm{D}_{3}$ partly precipitated in the acidic, aqueous solvent). Thereafter, the solution/suspension was partitioned with $10 \mathrm{~mL}$ of dichloromethane and another three times with $5 \mathrm{~mL}$ of dichloromethane. The combined organic phase was then passed through a small column filled with anhydrous sodium sulphate to remove residual water. After complete evaporation of dichloromethane, the residues were dissolved in $10 \mathrm{~mL}$ of methanol. Quizalofop-acid$\mathrm{D}_{3}$ was used as internal standard for quizalofop-acid and 3-OH-quizalofop-acid.

Stock solutions were prepared in methanol, those for 3-OH-CQO and 2,3-dihydroxy-quinoxaline in metha$\mathrm{nol} / 0.02 \mathrm{M} \mathrm{NaOH}(50 \% \mathrm{v} / \mathrm{v})$.

\section{Soil sampling}

Soil samples were collected in September 2016 at three locations from 10- to 15-year-old railway tracks in 


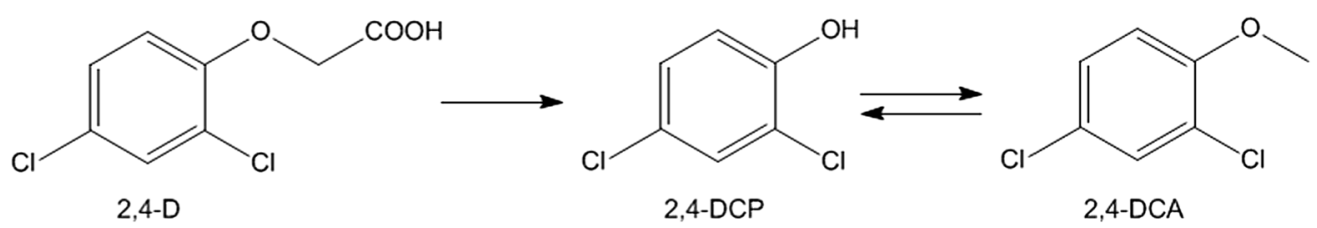<smiles>CCOC(=O)[C@H](C)Oc1ccc(Oc2cnc3cc(Cl)ccc3n2)cc1</smiles>

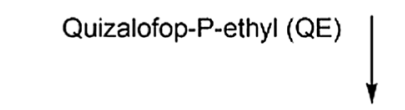<smiles>COc1ccc(O[C@@H](C)C(=O)O)cc1</smiles><smiles>O=C(O)CCc1ccc(Cl)cc1</smiles><smiles>C[C@H](Oc1ccc(Oc2nc3ccc(Cl)cc3nc2O)cc1)C(=O)O</smiles><smiles>O=C([O-])[O-]</smiles>

Fig. 1 Degradation pathway of 2,4-D and quizalofop-P-ethyl in soil

Switzerland. At location Münchenbuchsee (MBS), beigecolored subsoil with some rusty concretions was taken at a depth of $16-55 \mathrm{~cm}$ below the railway ballast. At Müntschemier (MR), white-beige subsoil was taken at a depth of 2-15 cm. From site Erlenbach (EB), we collected a $7-\mathrm{cm}$ thick layer of gray, sandy construction material below the ballast. Sampling depths were selected based on earlier construction geologic investigations with the aim to collect soils with high sand contents. Since the early 90s, weed control at these sites has been undertaken as spot treatments with glyphosate, and before that with atrazine. In addition to these three field samples, new crushed sand (CS), typically used in the construction of drainage channels in renovated tracks, was obtained from the Swiss Federal Railways. Some properties of the soils are listed in Table 1 (for convenience, we use the term "soil" for all four materials). The field-moist soils were sieved $(2 \mathrm{~mm})$ and stored in plastic bags at $4{ }^{\circ} \mathrm{C}$.

\section{Soil incubation}

Incubation experiments were set up 7-9 months after collection of the soils. Separate experiments were conducted with all test substances (2,4-D, quizalofop-Pethyl, and 5 metabolites) in all 4 soils, yielding a total of 28 incubations. Portions of $800 \mathrm{~g}$ field-moist soil were spread in a crystallizing dish (width, $23 \mathrm{~cm}$ ) and the test substance was applied evenly to the soil surface with a polyethylene spray bottle. For that, $800 \mu \mathrm{g} 2,4-\mathrm{D}$, quizalofop-P-ethyl, or quizalofop-P-acid, or $80 \mu \mathrm{g}$ 2,4-DCP, 2,4-DCA, 3-OH-quizalofop-acid, or 3-OH-CQO, were dissolved in $5-10 \mathrm{~mL}$ water (note that the spike solution of quizalofop-P-ethyl and quizalofop-P-acid contained $40 \%$ and $16 \%$ methanol, respectively). The resulting spike levels were $1 \mu \mathrm{g} / \mathrm{g}$ for 2,4-D, quizalofop-P-ethyl, and quizalofop-P-acid, and $0.1 \mu \mathrm{g} / \mathrm{g}$ for the other metabolites. After spiking, the soils were thoroughly mixed and filled into 2-L Erlenmeyer flasks that were closed with airpermeable cellulose plugs. The soils were then incubated at $20^{\circ} \mathrm{C}$ in the dark under aerobic conditions for up to 121 days. The soil moisture (adjusted 2 weeks before start 
Table 1 Properties of three soils from railway tracks and a crushed sand (fraction $<\mathbf{2} \mathbf{m m}$ )

\begin{tabular}{lllll}
\hline & Erlenbach EB & Münchenbuchsee MBS & Müntschemier MR & Crushed Sand CS \\
\hline Coordinates & $47^{\circ} 18^{\prime} 21^{\prime \prime} \mathrm{N}$ & $47^{\circ} 02^{\prime} 05^{\prime \prime} \mathrm{N}$ & $46^{\circ} 59^{\prime} 39^{\prime \prime} \mathrm{N}$ & - \\
& $8^{\circ} 35^{\prime} 31^{\prime \prime} \mathrm{E}$ & $7^{\circ} 25^{\prime} 09^{\prime \prime} \mathrm{E}$ & $7^{\circ} 08^{\prime} 17^{\prime \prime} \mathrm{E}$ & - \\
Altitude [m] & 418 & 532 & 434 & 83.5 \\
Sand [\%] & 78.5 & 60.5 & 25.7 & 11.9 \\
Silt [\%] & 13.5 & 24.2 & 9.1 & 4.6 \\
Clay [\%] & 8.0 & 15.3 & $<0.06$ & $<0.06$ \\
Organic carbon, $\mathrm{C}_{\text {org }}[\%]$ & 0.15 & 0.31 & 7.60 & 7.47 \\
$\mathrm{pH}\left(\mathrm{CaCl}_{2}\right)^{\mathrm{a}}$ & 7.67 & 7.64 & 0.24 & 0.20 \\
Water holding capacity [g water per g dry soil] & 0.24 & 0.28 & 4 & 36 \\
Cation exchange capacity [meq/100 g] $_{\text {Basal respiration [mg CO }}$-C/kg soil $\left.\times \mathrm{h}\right]^{\mathrm{b}}$ & 18 & 8 & 0.10 & 0.07 \\
\hline
\end{tabular}

a Suspension of soil in $0.01 \mathrm{M} \mathrm{CaCl}_{2}, 1: 5(\mathrm{w} / \mathrm{w})$

b Determined 11 weeks before start of degradation experiments

of the incubation experiments, Tables 2 and 3) was maintained by regular addition of distilled water. At appropriate time intervals, aliquots of $10 \mathrm{~g}$ soil were removed, filled into $20-\mathrm{mL}$ glass vials, and stored in a freezer at $-20{ }^{\circ} \mathrm{C}$ until extraction. To samples from incubation studies with 2,4-D, 2,4-DCP, and 2,4-DCA, 10 mL methanol were added immediately after sampling to minimize possible volatilization of the metabolites during storage.

\section{Extraction of 2,4-D and metabolites}

All samples of an incubation experiment with a particular compound were processed on the same day. The methanolic soil suspensions were fortified with internal standards $\left(1 \mu \mathrm{g}\right.$ 2,4-D-D $, 2,4-\mathrm{DCP}-\mathrm{D}_{3}$, and 2,4-DCA-D in $100 \mu \mathrm{L}$ methanol). After vigorous shaking $(\approx 1 \mathrm{~min})$, the suspensions were centrifuged $(\approx 1500 \mathrm{~g}$ for $5 \mathrm{~min}$; Eppendorf 5804, Hamburg, Germany) and the supernatants were transferred to $40-\mathrm{mL}$ glass vials. A second extraction was performed with $10 \mathrm{~mL}$ deionized water, followed by $7 \mathrm{~min}$ centrifugation. The combined extracts were then acidified with $\mathrm{H}_{2} \mathrm{SO}_{4}(1: 4$ in water) to $\mathrm{pH} \approx 2$ and partitioned with $10 \mathrm{~mL}$ dichloromethane and then a second time with $5 \mathrm{~mL}$ dichloromethane. The combined dichloromethane phases were evaporated to $\approx 200 \mu \mathrm{L}$ on a heating plate under a gentle stream of nitrogen. After addition of $50 \mu \mathrm{L} 0.5 \%$ trifluoroacetic acid in methanol, the samples were derivatized using approximately $1 \mathrm{~mL}$ diazoethane in methyl tert-butyl ether (for $30 \mathrm{~min}$, preparation described in [23]). Then, the reaction mixture was allowed to evaporate to $\approx 200 \mu \mathrm{L}$. After addition of $\approx 100 \mathrm{mg}$ of anhydrous sodium sulphate, the samples were quantitatively transferred with hexane to $1.5-\mathrm{mL}$ clear glass autosampler vials. Once more the solvent volume was reduced to $\approx 200 \mu \mathrm{L}$ and filled up to $1 \mathrm{~mL}$ with hexane.

\section{Extraction of quizalofop-ethyl and metabolites}

As for 2,4-D and metabolites, all samples of an incubation experiment were processed on the same day. The soil samples $(10 \mathrm{~g})$ were suspended in $10 \mathrm{~mL}$ methanol, internal standards (1 $\mu \mathrm{g}$ each of quizalofop-ethyl$\mathrm{D}_{3}$ and quizalofop-acid- $\mathrm{D}_{3}$ in $100 \mu \mathrm{L}$ methanol and $1 \mu \mathrm{g}$ 2,3-dihydroxy-quinoxaline in $100 \mu \mathrm{L}$ methanol/ water $(50 \% \mathrm{v} / \mathrm{v}))$ were added, and the vials were vigorously shaken $(\approx 1 \mathrm{~min})$ and then centrifuged $(\approx 1500 \mathrm{~g}$ for $10 \mathrm{~min}$ ). The supernatants were transferred to $20-\mathrm{mL}$ glass vials. A second extraction was performed with $10 \mathrm{~mL}$ aqueous $0.01 \mathrm{M} \mathrm{CaCl}_{2}$, followed by $10 \mathrm{~min}$ centrifugation. Aliquots of $0.4 \mathrm{~mL}$ of the combined extracts were then transferred to $1.5-\mathrm{mL}$ clear glass autosampler vials and diluted with $0.6 \mathrm{~mL}$ water.

\section{GC-MS analysis of 2,4-D and metabolites}

2,4-D (as ethyl ester), 2,4-DCP (as ethyl ether), 2,4-DCA, and the corresponding internal standards were analysed on a GC-MS/MS system consisting of a PAL autosampler (CTC Analytics, Zwingen, Switzerland), a HP6890N gas chromatograph (Agilent Technologies, Santa Clara, CA), and a Quattro Micro mass spectrometer (Waters Corporation, Milford, MA). GC conditions were as follows: 1 $\mu \mathrm{L}$ split/splitless injection $\left(250{ }^{\circ} \mathrm{C}\right.$, initial $60 \mathrm{~s}$ splitless); 30-m column (internal diameter, $320 \mu \mathrm{m}$ ), coated with (5\%-phenyl)-methylpolysiloxane with a film thickness of $0.25 \mu \mathrm{m}$ (BGB5, BGB Analytics, Boeckten, Switzerland); temperature program: $50{ }^{\circ} \mathrm{C}, 2 \mathrm{~min}$ isothermal, $25^{\circ} \mathrm{C} / \mathrm{min}$ to $90{ }^{\circ} \mathrm{C}, 5{ }^{\circ} \mathrm{C} / \mathrm{min}$ to $160{ }^{\circ} \mathrm{C}, 25^{\circ} \mathrm{C} / \mathrm{min}$ to $280{ }^{\circ} \mathrm{C}$; constant flow, $4 \mathrm{~mL} / \mathrm{min}$ helium. 
Table 2 Panel A: Half-lives (DT ${ }_{50}$ ) and DT 90 values of 2,4-D, 2,4-DCP, and 2,4-DCA. Panel B: Half-lives (DT 50 ) and formation fractions of metabolites resulting from sequential fitting, not considering the reversibility of the reaction 2,4-DCP to 2,4DCA

Panel A

\begin{tabular}{|c|c|c|c|c|c|c|c|c|}
\hline & \multirow{2}{*}{$\begin{array}{l}\mathrm{pH} \\
\left(\mathrm{CaCl}_{2}\right)\end{array}$} & \multirow{2}{*}{$\begin{array}{l}C_{\text {org }} \\
{[\%]}\end{array}$} & \multirow{2}{*}{$\begin{array}{l}T\left[{ }^{\circ} \mathrm{C}\right] / \\
M[\%]\end{array}$} & & \multicolumn{4}{|c|}{$\mathrm{DT}_{50} / \mathrm{DT}_{90}$ [days], best fit ${ }^{\mathrm{a}}$} \\
\hline & & & & & \multicolumn{2}{|l|}{$2,4-D$} & 2,4-DCP & 2,4-DCA \\
\hline \multicolumn{9}{|l|}{ Soils from railway tracks } \\
\hline$E B$ & 7.7 & 0.15 & $20 / 35$ & & \multicolumn{2}{|c|}{ 35/115 SFO } & 27/129 DFOP & $82 / 271 \mathrm{SFO}$ \\
\hline MBS & 7.6 & 0.31 & $20 / 60$ & & \multicolumn{2}{|c|}{ 39/131 SFOc } & 1.0/7.0 FOMC & $9.2 / 31 \mathrm{SFO}$ \\
\hline MR & 7.6 & $\approx 0.04$ & $20 / 72$ & & \multicolumn{2}{|c|}{$>1000 />1000 \mathrm{SFO}^{c}$} & 4.1/18 DFOP & $0.3 / 2.1 \mathrm{DFOP}$ \\
\hline \multirow[t]{2}{*}{ CS } & 7.5 & $<0.06$ & $20 / 65$ & & $203 / 675$ & $5 \mathrm{SFO}^{\mathrm{C}}$ & 66/519 FOMC & $101 / 335$ SFO \\
\hline & & & & & \multicolumn{4}{|c|}{$\mathrm{DT}_{50}$ [days], modeling endpoints ${ }^{\mathrm{b}}$} \\
\hline Geom. mean, $20^{\circ} \mathrm{C}, \mathrm{pF} 2$ & & $\approx 0.1$ & & & 115 & & 12 & 14 \\
\hline \multicolumn{9}{|l|}{ Agricultural soils [13] } \\
\hline Min-max & $6.2-7.8^{d}$ & $0.9-3.7$ & $20 / 50$ & & \multicolumn{2}{|l|}{$1.6-95$} & $3.2-6.2$ & $11-16$ \\
\hline \multicolumn{2}{|c|}{ Geom. mean, $20^{\circ} \mathrm{C}, \mathrm{pF} 2$} & \multicolumn{2}{|l|}{$1.5 / 1.8 / 1.8^{\mathrm{e}}$} & & \multicolumn{2}{|l|}{4.4} & 7.0 & 10 \\
\hline \multicolumn{9}{|l|}{ Panel B } \\
\hline & \multicolumn{2}{|c|}{ Sequence of fitting } & $\begin{array}{l}\left.\mathrm{DT}_{50} \text { [days }\right] \\
2,4-\mathrm{D}^{\mathrm{f}}\end{array}$ & $\begin{array}{l}\text { For } \\
\text { frac }\end{array}$ & $\begin{array}{l}\text { tion } \\
\text { on [\%] }\end{array}$ & $\begin{array}{l}\mathrm{DT}_{50} \text { [days] } \\
2,4-\mathrm{DCP}\end{array}$ & $\begin{array}{l}\text { Formation } \\
\text { fraction [\%] }\end{array}$ & $\begin{array}{l}\mathrm{DT}_{50} \text { [days] } \\
2,4-\mathrm{DCA}^{f}\end{array}$ \\
\hline \multirow[t]{2}{*}{ EB } & \multirow{2}{*}{\multicolumn{2}{|c|}{$\begin{array}{l}2,4-\mathrm{D} \rightarrow 2,4-\mathrm{DCP} \rightarrow 2,4-\mathrm{DCA} \rightarrow \operatorname{sink} \\
2,4-\mathrm{DCP} \rightarrow 2,4-\mathrm{DCA} \rightarrow \operatorname{sink}\end{array}$}} & $35 \mathrm{SFO}$ & 34 & & $35 \mathrm{SFO}$ & 32 & $33 \mathrm{SFO}$ \\
\hline & & & & & & $28 \mathrm{DFOP}$ & 12 & 103 SFO \\
\hline \multirow[t]{2}{*}{ MBS } & \multicolumn{2}{|c|}{$2,4-D \rightarrow 2,4-D C P \rightarrow \sin k$} & $40 \mathrm{SFO}^{\mathrm{C}}$ & 16 & & $2.6 \mathrm{SFO}^{\mathrm{c}}$ & & \\
\hline & \multicolumn{2}{|c|}{$2,4-D C P \rightarrow 2,4-D C A \rightarrow \operatorname{sink}$} & & & & 1.0 FOMC & 6.4 & $16 \mathrm{SFO}$ \\
\hline \multirow[t]{2}{*}{ MR } & \multicolumn{3}{|c|}{$2,4-\mathrm{DCP} \rightarrow 2,4-\mathrm{DCA} \rightarrow \operatorname{sink}$} & & & 4.1 DFOP & 2.2 & $11 \mathrm{SFO}$ \\
\hline & \multicolumn{3}{|c|}{$2,4-D C A \rightarrow 2,4-D C P \rightarrow \operatorname{sink}$} & & & $4.8 \mathrm{SFO}$ & $79^{h}$ & 0.3 DFOP \\
\hline CS & \multicolumn{3}{|c|}{$2,4-\mathrm{DCP} \rightarrow 2,4-\mathrm{DCA} \rightarrow \sin \mathrm{k}$} & & & 66 FOMC & 2.5 & $101 \mathrm{SFO}$ \\
\hline
\end{tabular}

$T$ : temperature, $M$ : moisture in $\%$ of water holding capacity

a SFO: single first-order kinetics, DFOP: double first-order in parallel model, FOMC: first-order multi-compartment model. $X^{2}$ values $<10 \%$

b Calculated according to [26], for details see Additional file 1: Table S4 and Additional file 2: Kinetic fits

c Only the slow initial phase was considered

d Measured in $\mathrm{H}_{2} \mathrm{O}$

e In degradation studies with 2,4-D/2,4-DCP/2,4-DCA

${ }^{f}$ Best fit. $X^{2}$ values $<12 \%$, except for $2,4-$ DCA in CS (20\%)

$g$ Volatilization may have contributed to overall dissipation (i.e., actual formation may have been higher)

h Back reaction from 2,4-DCA to 2,4-DCP

The MS was operated in electron impact ionization $\left(70 \mathrm{eV}, 180{ }^{\circ} \mathrm{C}\right)$ and selected-ion-monitoring mode. 2,4-D-ethyl, 2,4-D-D ${ }_{3}$-ethyl, 2,4-DCP-ethyl, 2,4-DCP$\mathrm{D}_{3}$-ethyl, 2,4-DCA, and 2,4-DCA- $\mathrm{D}_{3}$ were quantified using the ions $\mathrm{m} / z 248$ (175 for confirmatory purposes), 253 (180), 162 (190), 167 (195), 176 (161), and 181 (166), respectively. As the mass differences between target compounds and deuterated internal standards are small, the masses of the ${ }^{37} \mathrm{Cl}^{35} \mathrm{Cl}$ - rather than the ${ }^{35} \mathrm{Cl}_{2}$ isotopologues were selected for the internal standards to minimize interferences. A typical chromatogram of a soil extract is shown in Additional file 1: Fig. S1 (left). Quantification was based on peak area ratios relative to the internal standards and in reference to suitable standard solutions. Information on recoveries, precision, storage stability, and limits of quantification are given in the Additional file 1.

\section{LC-MS/MS analysis of quizalofop-ethyl and metabolites}

Quizalofop-ethyl, the three metabolites, and the corresponding internal standards were analysed with liquid chromatography-tandem mass spectrometry. The instrument was configured with an autosampler (HTS PAL, CTC), a binary HPLC pump (Agilent 1100, with microvacuum degasser), and a triple quadrupole mass spectrometer (API 4000, with turbo ion spray source, Sciex, 
Table 3 Panel A: Half-lives $\left(\mathrm{DT}_{50}\right)$ and $\mathrm{DT}_{90}$ values of QE, QA, 3-OH-QA, and 3-OH-CQO. Panel B: Half-lives (DT 50 ) and formation fractions of metabolites resulting from sequential fitting

\begin{tabular}{|c|c|c|c|c|c|c|c|}
\hline \multicolumn{8}{|l|}{ Panel A } \\
\hline & \multirow{2}{*}{$\begin{array}{l}\mathrm{pH} \\
\left(\mathrm{CaCl}_{2}\right)\end{array}$} & \multirow{2}{*}{$\begin{array}{l}C_{\text {org }} \\
{[\%]}\end{array}$} & \multirow{2}{*}{$\begin{array}{l}T\left[{ }^{\circ} \mathrm{C}\right] / \\
M[\%]\end{array}$} & \multicolumn{4}{|c|}{$\mathrm{DT}_{50} / \mathrm{DT}_{90}\left[\right.$ days], best fit ${ }^{\mathrm{a}}$} \\
\hline & & & & QE & QA & 3-OH-QA & 3-OH-CQO \\
\hline \multicolumn{8}{|c|}{ Soils from railway tracks } \\
\hline $\mathrm{EB}$ & 7.7 & 0.15 & $20 / 49$ & $21 />1000 \mathrm{FOMC}$ & 96/414 DFOP & $37 / 122 \mathrm{SFO}$ & $335 />1000 \mathrm{FOMC}$ \\
\hline MBS & 7.6 & 0.31 & $20 / 54$ & $0.22 / 1.4$ DFOP & 113/488 DFOP & $35 / 116$ SFO & 24/> 1000 FOMC \\
\hline $\mathrm{MR}$ & 7.6 & $\approx 0.04$ & $20 / 67$ & $0.21 / 0.98$ FOMC & $>1000 />1000 \mathrm{SFO}$ & $630 />1000 \mathrm{SFO}$ & $445 />1000$ SFO \\
\hline \multirow[t]{2}{*}{ CS } & 7.5 & $<0.06$ & $20 / 55$ & $0.69 / 68$ FOMC & $371 />1000 \mathrm{SFO}$ & 189/628 SFO & $474 />1000$ FOMC \\
\hline & & & & \multicolumn{4}{|c|}{$\mathrm{DT}_{50}$ [days], modeling endpoints ${ }^{\mathrm{b}}$} \\
\hline $\begin{array}{l}\text { Geom. mean, } 20^{\circ} \mathrm{C} \text {, } \\
\text { pF } 2\end{array}$ & & $\approx 0.1$ & & 4.0 & 276 & 101 & 246 \\
\hline \multicolumn{8}{|l|}{ Agricultural soils [17] } \\
\hline Min-max & $5.0-8.2^{c}$ & $0.8-4.6$ & $\begin{array}{l}20-22 / 40- \\
70\end{array}$ & $0.3-1.1$ & $7-182$ & $7-69$ & $42-258$ \\
\hline $\begin{array}{l}\text { Geom. mean, } 20^{\circ} \mathrm{C} \text {, } \\
\text { pF } 2\end{array}$ & & $2.8 / 1.9 / 1.5 / 2.1^{d}$ & & 0.4 & 24 & 18 & 63 \\
\hline
\end{tabular}

Panel B

\begin{tabular}{|c|c|c|c|c|c|c|}
\hline & sequence of fitting & $\begin{array}{l}\left.\mathrm{DT}_{50} \text { [days }\right] \\
\mathrm{QE}^{\mathrm{e}}\end{array}$ & $\begin{array}{l}\text { Formation } \\
\text { fraction [\%] }\end{array}$ & $\begin{array}{l}\mathrm{DT}_{50} \text { [days] } \\
\mathrm{QA}^{\mathrm{e}}\end{array}$ & $\begin{array}{l}\text { Formation } \\
\text { fraction [\%] }\end{array}$ & $\begin{array}{l}\mathrm{DT}_{50} \text { [days] } \\
3-\mathrm{OH}-\mathrm{QA}^{\mathrm{e}}\end{array}$ \\
\hline EB & $\mathrm{QE} \rightarrow \mathrm{QA} \rightarrow 3-\mathrm{OH}-\mathrm{QA} \rightarrow \sin \mathrm{k}$ & $28 \mathrm{FOMC}$ & 100 & $92 \mathrm{SFO}$ & 0.5 & $180 \mathrm{SFO}$ \\
\hline MBS & $\mathrm{QE} \rightarrow \mathrm{QA} \rightarrow 3-\mathrm{OH}-\mathrm{QA} \rightarrow \sin \mathrm{k}$ & $0.20 \mathrm{DFOP}$ & 100 & 105 SFO & 3.0 & 91 SFO \\
\hline MR & $\mathrm{QE} \rightarrow \mathrm{QA} \rightarrow \sin \mathrm{k}$ & $0.21 \mathrm{DFOP}$ & 98 & 968 SFO & & \\
\hline CS & $\mathrm{QE} \rightarrow \mathrm{QA} \rightarrow \sin \mathrm{k}$ & $1.1 \mathrm{FOMC}$ & 100 & 746 SFO & & \\
\hline
\end{tabular}

T: temperature, M: moisture in \% of water holding capacity

a SFO: single first-order kinetics, DFOP: double first-order in parallel model, FOMC: first-order multi-compartment model. $X^{2}$ values $<10 \%$

b Calculated according to [26], for details see Additional file 1: Table S5 and Additional file 2: Kinetic fits

c Measured in $\mathrm{H}_{2} \mathrm{O}$

d In degradation studies with QE/QA/3-OH-QA/3-OH-CQO

e Best fit. $X^{2}$ values $\leq 12 \%$, except for $3-\mathrm{OH}-\mathrm{QA}$ in MBS (16\%)

Framingham, MA). LC conditions were as follows: injection via a $100 \mu \mathrm{L}$ PEEK loop; Gemini NX column (C18, $150 \times 2 \mathrm{~mm}, 5 \mu \mathrm{m}$ particle size, protected by a $4 \times 2 \mathrm{~mm}$ pre-column with the same stationary phase, Phenomenex, Torrance, CA); gradient elution with the solvents formic acid ( $1 \% \mathrm{v} / \mathrm{v}$ in water) and methanol (initial conditions, $20 \%$ methanol, linear increase to $85 \%$ during $6.5 \mathrm{~min}$, linear increase to $100 \%$ during $4 \mathrm{~min}, 3 \mathrm{~min}$ isocratic hold, initial conditions re-established within $1 \mathrm{~min}$, followed by an equilibration time of $5 \mathrm{~min}$ ); flow, $0.2 \mathrm{~mL} / \mathrm{min}$.

The MS was operated in negative (ion spray voltage, $\left.-4.2 \mathrm{kV}, 400{ }^{\circ} \mathrm{C}\right)$ or positive mode $\left(5 \mathrm{kV}, 400{ }^{\circ} \mathrm{C}\right.$; only for detection of quizalofop-ethyl; time window, 11-12 min) and the ion transitions listed in Additional file 1: Table S1 were monitored. As for 2,4-D and metabolites, the mass differences between target compounds and deuterated internal standards are small. Therefore, the ion transitions of the ${ }^{37} \mathrm{Cl}$ - rather than the ${ }^{35} \mathrm{Cl}$-isotopologues were selected for the internal standards to minimize interferences.
A representative chromatogram of a soil extract is shown in Additional file 1: Fig. S1 (right). Quantification was based on peak area ratios relative to the internal standards and in reference to matrix-matched standard solutions. For that, untreated soil was extracted as described above and target compounds and internal standards were added to the extracts directly before transfer to the autosampler vial and dilution with water. For quality assurance data, see Additional file 1.

\section{Soil adsorption experiments}

Batch adsorption experiments were performed in accordance with OECD guideline 106 at $20{ }^{\circ} \mathrm{C}$ in the dark [24]. Separate experiments were performed with all test substances (2,4-D, quizalofop-P-ethyl, and 5 metabolites) in all 4 soils, at 5 concentration levels each and in duplicate, yielding a total of 280 batch adsorption tests. In all tests, the indirect method was used, where only the remaining 
concentration in the aqueous phase was measured after achievement of adsorption equilibrium.

The water content of the sieved, field-moist soils was accounted for in the calculation of soil:solution ratios. Typically, aliquots of moist soil corresponding to $10 \mathrm{~g}$ dry weight were weighed into $40 \mathrm{~mL}$ clear glass vials with Teflon-lined screw caps. To these soils, aqueous $0.01 \mathrm{M} \mathrm{CaCl}_{2}$ solution was added to yield a water volume of exactly $9 \mathrm{~mL}$ (including the water content of the soil samples). The vials were capped, mounted on a reciprocal shaker ( 90 oscillations/min), and agitated for $24 \mathrm{~h}$ for preequilibration. Then, $1 \mathrm{~mL}$ of spiking solution containing the test substance was added (resulting soil:solution ratio, 1:1) and the vials were agitated for an additional $24 \mathrm{~h}$. The soil slurries were then centrifuged at $\approx 1500 \mathrm{~g}$ for $10 \mathrm{~min}$ and an aliquot of the clear supernatant was transferred to an autosampler vial, where internal standard was added. The solutions were analysed by LC-MS/MS. Preliminary experiments with 2,4-DCA indicated that volatilisation may have affected the solute concentrations in some samples. Therefore, smaller vials $(20 \mathrm{~mL})$ were used for the experiments to minimise the air volume above the soil suspension. The same precautionary measures were used for 2,4-DCP.

Further deviations from this procedure included (i) different soil:solution ratios (Additional file 1: Table S3), (ii) different equilibration times (for substances with low stability, Additional file 1: Table S3), and (iii) analysis by GC-MS, after liquid-liquid extraction with dichloromethane and solvent exchange to hexane (only 2,4DCA). More details on preliminary tests, adsorption isotherms, and LC-MS/MS analysis of 2,4-D and 2,4DCP are given in the Additional file 1.

\section{Kinetic analysis}

Kinetic parameters for the degradation of the individual test substances as well as metabolites formed during the experiments were determined using the software Cake [25]. For the incubated substances, we tested the single first-order model (SFO), the double first-order in parallel model (DFOP, this bi-phasic model assumes two compartments in which the compound is degraded according to first-order kinetics, but with different rate constants [26]), the first-order multi-compartment model (FOMC, this bi-phasic model assumes a continuum of micro-compartments in which the compound is degraded according to first-order kinetics [27]), and the hockey-stick model (HS, this bi-phasic model assumes two sequential firstorder curves with a breakpoint at a certain time [26]), whereas for metabolites formed during the experiments, we always used SFO kinetics. To determine kinetic formation fractions of metabolites, their concentrations were expressed in "parent" equivalents (note that a formation fraction is defined here as the molar fraction of a test substance being transformed to a respective metabolite). Initial concentrations were adjustable, those of the metabolites were set to 0). For fitting, the iteratively reweighted least squares optimizer was selected. Fits were only accepted, when statistically significant parameters (based on the $95 \%$ confidence interval) could be determined, with a $\chi^{2}$ error $<15 \%$ [26]. Visual assessment and residuals were further acceptance criteria. Two types of $\mathrm{DT}_{50}$ values (half-lives) were derived: (i) values resulting from the best-fitting model for optimal description of the degradation curves and (ii) more conservative values describing the slow phase of degradation in case of bi-phasic kinetics. The latter are generally used in leaching models (so-called modeling endpoints) and served here also for a comparison of data for railway soils with agricultural soils.

\section{Results and discussion \\ Worst-case character of the railway soils with regard to sorption and degradation}

The soils used in this study exhibited high sand (61-84\%) and low clay (5-15\%) contents and, consequently, low water holding capacities $(0.2-0.3 \mathrm{~g} / \mathrm{g}$, Table 1$)$, properties which lead to rapid vertical transport of water. Similar soil textures were also assumed in three scenarios that were developed for authorization of herbicides on railway tracks in Germany [28]. These scenarios were implemented in the computer model PELMO that simulates possible leaching of pesticides in soil.

The $\mathrm{pH}$-values of our railway soils were high (7.5-7.7) so that weak acids (e.g., quizalofop-P-acid, 2,4-D, or 2,4DCP) were present in their more mobile, anionic form. Sorption is, therefore, expected to be weaker than in acidic soils. Furthermore, the organic carbon contents of $<0.06-0.31 \%$ (Table 1 ) were among the lowest values reported for subsoils below railway tracks $(0.06-2.3 \%$ for the fine material) $[18,28-30]$. Low organic carbon and low clay contents are expected to result in weak sorption of most organic compounds.

Finally, the basal respiration, a measure for the microbial activity of soils, varied from 0.07 to $0.11 \mathrm{mg} \mathrm{CO}_{2}-\mathrm{C} /$ $\mathrm{kg} / \mathrm{h}$ (Table 1) and was thus in the range of values reported for Swedish railway soils $\left(0.01-0.32 \mathrm{mg} \mathrm{CO}_{2}-\mathrm{C} /\right.$ $\mathrm{kg} / \mathrm{h}$ ) [30], but clearly lower than in agricultural topsoils [31].

Overall, the soils selected represent a realistic worstcase regarding sorption and degradation of organic compounds for the use on railway tracks. However, the soil properties intentionally deviate from those recommended to study degradation of pesticides in agricultural soils, e.g., according to OECD guideline 307 on aerobic and anaerobic transformation in soil, particularly in 
terms of organic matter content and range of textures and $\mathrm{pH}$ values [32].

\section{Degradation of 2,4-D and its metabolites in railway soils} Degradation of 2,4-D differed considerably in the four soils (Fig. 2, left). In soil MR and the crushed sand (CS), a pronounced lag-phase was observed with no or very slow initial degradation, followed by a sharp decline in concentration after about 100 and $50 \mathrm{~d}$, respectively. An initial phase with slower degradation was also found in soil MBS (and, to a certain degree, in EB).

Bi-phasic degradation of pesticides in soil incubation studies normally goes along with a deceleration over time [26]. Occasionally, also an increase of the degradation rate is observed [33]. Microorganisms may require a certain adaptation time to cope with contaminants such as 2,4-D. When transferring the soils from the railway tracks into the laboratory environment, the conditions for microorganisms are changed. In particular, the soil structure is disturbed by sieving, with a possible negative impact on microorganisms. After some time, however, microorganisms may recover and eventually be capable of degrading 2,4-D. Also note that the soils had been stored for 7-9 months prior to start of the incubation experiments which may have affected certain microorganisms.

On the other hand, the observed sharp decline may also be the result of another laboratory artifact. Microorganisms, which were originally not present in the soil, may have been introduced during collection, sieving, sampling, or moisturizing, which may have altered the degradation behavior. It is thus not clear whether such a pronounced increase in the degradation rate of 2,4-D would also occur under natural conditions in soils below railway tracks.
In the kinetic analysis, we considered the slow initial phase as representative for natural conditions, which resulted in conservative estimates of the $\mathrm{DT}_{50}$ and $\mathrm{DT}_{90}$ values in the respective soils (Table 2, Panel A; $\mathrm{DT}_{\mathrm{x}}$ is defined as the time required for $x \%$ dissipation). The $\mathrm{DT}_{50}$ values in this initial phase ranged from $39 \mathrm{~d}$ in MBS to $203 \mathrm{~d}$ in CS, while in MR, no degradation was observed during the initial $84 \mathrm{~d}(>1000 \mathrm{~d})$. For soil EB, even though visually bi-phasic, an $\mathrm{SFO} \mathrm{DT}_{50}$ of the entire experimental duration was considered adequate.

Dissipation of 2,4-DCP, the primary metabolite of 2,4$D$, when applied as test substance, was consistently faster, particularly in soils MBS and MR (Fig. 2, second panel). For 2,4-DCP, a bi-phasic decline was observed as well, but with the more typical deceleration over time. The dissipation curves were well described with the bi-phasic DFOP or FOMC model, resulting in $\mathrm{DT}_{50}$ values of 1-66 days (Table 2, Panel A). $\mathrm{DT}_{90}$ values ranged from 7 to $519 \mathrm{~d}$, indicating the clearly slower degradation at later time points.

$\mathrm{DT}_{50}$ values of 2,4-DCA, the secondary metabolite of 2,4-D, also varied considerably between soils, with very fast elimination in $\mathrm{MR}\left(\mathrm{DT}_{50}, 0.3\right.$ days), but slow elimination in CS (101 days). 2,4-DCA concentrations could be adequately described by the SFO model, except for soil MR, where a better fit was obtained with the DFOP model (Fig. 2, right; Table 2, Panel A). $\mathrm{DT}_{90}$ values were between 2 and 335 days.

\section{Comparison with agricultural soils}

The European "Forum for the coordination of pesticide fate models and their use" (FOCUS) recommends that, in case of bi-phasic degradation, only the slow phase should be considered when deriving $\mathrm{DT}_{50}$ values for groundwater assessments [26]. Furthermore, $\mathrm{DT}_{50}$ values shall be
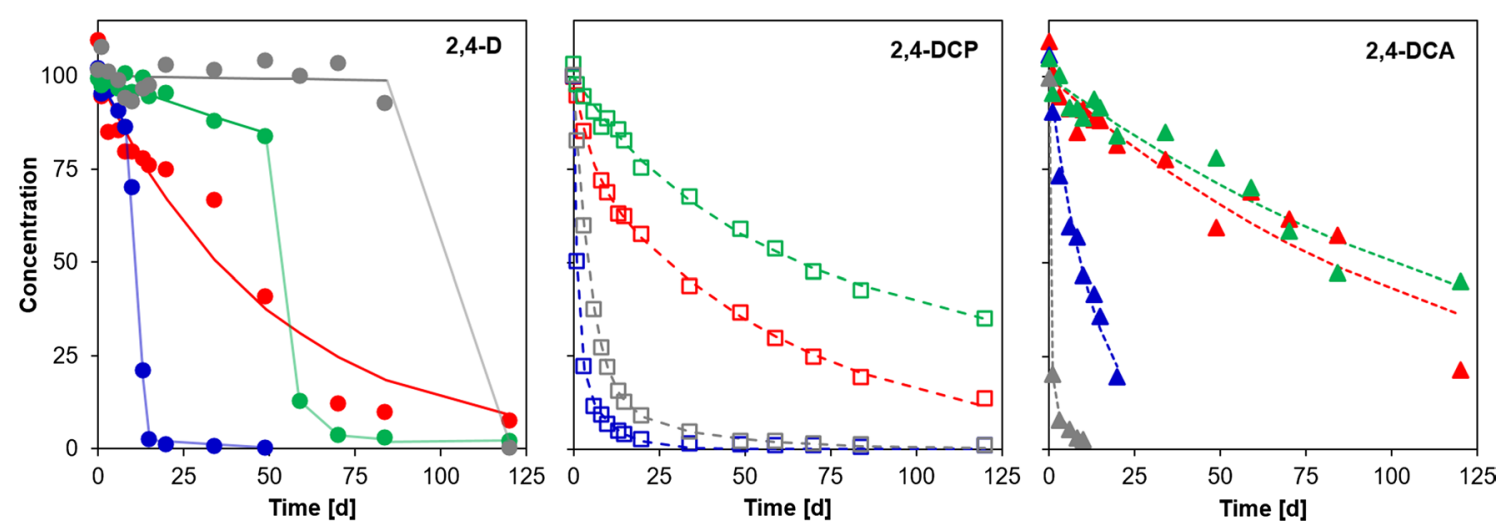

Fig. 2 Degradation of 2,4-D, 2,4-DCP, and 2,4-DCA in soils from railway tracks and a crushed sand. EB: red, MBS: blue, MR: grey, CS: green. Symbols show measured concentrations, lines are kinetic fits (for 2,4-D, only the slow initial phase was fitted, the following data points are linked by straight lines) 
normalized to a reference temperature of $20{ }^{\circ} \mathrm{C}$ and a reference moisture of $\mathrm{pF} 2$, and the geometric mean of the normalized $\mathrm{DT}_{50}$ values shall be used in pesticide leaching models (modeling endpoints) [34]. Following these recommendations, we determined conservative geomean $\mathrm{DT}_{50}$ values of 115,12 , and $14 \mathrm{~d}$ for 2,4-D, 2,4-DCP, and 2,4-DCA (Table 2, Panel A).

These values were then compared with $\mathrm{DT}_{50}$ values typically found in agricultural soils. For 2,4-D, numerous studies are available in public literature [21]. However, for a robust comparison, we used kinetic endpoints from studies that were performed for registration of 2,4-D in Europe [13] as these studies were evaluated according to the above cited recommendations of FOCUS. Degradation of 2,4-D was considerably slower in our railway soils than in these agricultural soils (on average by a factor of 26, Table 2, Panel A), which was expected based on the fact that the microbial activity (approximated by the measured basal respiration) was at least one order of magnitude lower in the railway soils (Table 1 ) than in agricultural soils. Nonetheless, 2,4-D showed a remarkably slow degradation in our soils. To what extent this may be the consequence of the experimental conditions in the laboratory, cannot be answered here (see the above discussion on the lag-phase). Elimination of the metabolites 2,4-DCP and 2,4-DCA was, however, only 1.7 and $1.4 \times$ slower in the railway soils than in agricultural soils, respectively (again based on geomean $\mathrm{DT}_{50}$ values, Table 2, Panel A).

\section{Formation of 2,4-D metabolites}

Highest amounts of 2,4-D metabolites were observed in soil EB, where 2,4-DCP reached $14 \%$ after $49 \mathrm{~d}$ and 2,4DCA $2.6 \%$ after $120 \mathrm{~d}$ (Fig. 3, left; formation expressed in "parent" equivalents). In the other soils, metabolites were found in much lower amounts of $\approx 1 \%(2,4-\mathrm{DCP})$ and $<0.5 \% \quad(2,4-\mathrm{DCA})$. In incubation experiments with 2,4-DCP, the secondary metabolite 2,4-DCA was observed in amounts of up to 7\% in EB (Fig. 3, second panel), $5 \%$ in MBS, and $1 \%$ in MR and CS. However, the methylation of 2,4-DCP to 2,4-DCA was reversible, particularly in soils MR and CS, with considerable formation of 2,4-DCP in incubation experiments with 2,4-DCA (up to 55 and $22 \%$, respectively, Fig. 3, right).

Kinetic parameters for formation and further degradation of metabolites were fitted assuming sequential reactions $(2,4-\mathrm{D} \rightarrow 2,4-\mathrm{DCP} \rightarrow 2$,4-DCA, 2,4-DCP $\rightarrow 2$,4DCA, or 2,4-DCA $\rightarrow 2,4-D C P)$. Statistically significant $\mathrm{DT}_{50}$ values and formation fractions could be determined in a number of experiments and corresponding results are given in Table 2 (Panel B). Some fits of experiments with notable metabolite formation are depicted in Fig. 3.

For the transformation from 2,4-D to 2,4-DCP, kinetic formation fractions of $34 \%$ and $16 \%$ were obtained for soils EB and MBS, respectively. The subsequent transformation from 2,4-DCP to 2,4-DCA occurred with highly differing formation fractions of $2-32 \%$, again with the highest formation in soil EB. For the back reaction from 2,4-DCA to 2,4-DCP, only one statistically significant formation fraction could be derived, which was $79 \%$ in soil MR. Note that 2,4-DCP and 2,4-DCA formed from the respective precursors may have volatilized to some extent (see Additional file 1) and formation fractions including volatilization may have been higher.

$\mathrm{DT}_{50}$ values resulting from sequential fitting generally were in good agreement with $\mathrm{DT}_{50}$ values determined in experiments with direct incubation of the respective compounds (Table 2, Panel A and Panel B). Differences were primarily observed when a bi-phasic model was used in direct incubation experiments and SFO kinetics in experiments with a precursor compound. Such differences are commonly observed, even if the same kinetic
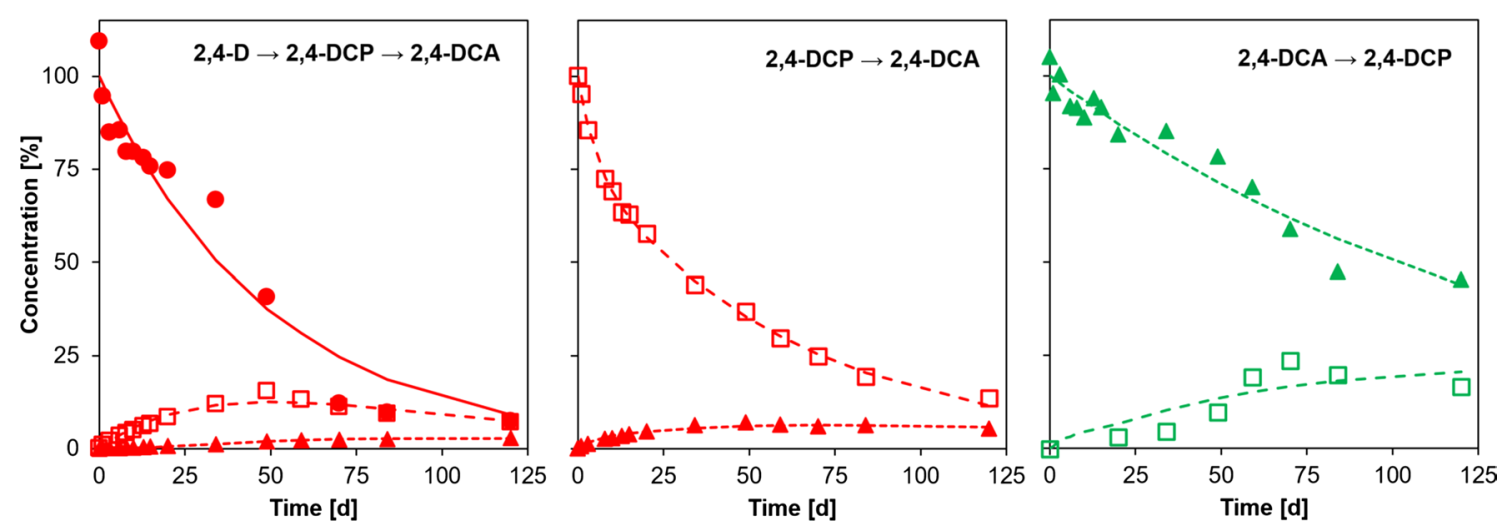

Fig. 3 Sequential degradation of 2,4-D to 2,4-DCP and 2,4-DCA. Left: 2,4-D to 2,4-DCP and 2,4-DCA in soil EB. Middle: 2,4-DCP to 2,4-DCA in EB. Right: back-reaction 2,4-DCA to 2,4-DCP in CS. Symbols show measured concentrations, lines are kinetic fits 
model is used for fitting. Half-lives may indeed be different, whether a compound is directly spiked to a soil or formed in soil from a precursor $[35,36]$.

In the kinetic analysis of the experiments with 2,4-D and its metabolites, the reversibility of the reaction from 2,4-DCP to 2,4-DCA should, in principle, be considered. However, in many experiments, formation of at least one of the two metabolites was too low for such a kinetic analysis. In other experiments, the kinetic analysis did not result in statistically significant fitting parametersfor example, in incubation experiments with 2,4-DCP and 2,4-DCA in soil MR. Note that the model Aquasim [37] was used to consider the interconversion of the two metabolites, with a similar approach as in $[35,38]$.

\section{Degradation of quizalofop-P-ethyl and its metabolites in railway soils}

Degradation curves of quizalofop-P-ethyl (QE), quizalofop-P-acid (QA), 3-OH-QA, and 3-OH-CQO in the four railway soils are shown in Fig. 4. Most experiments were better fitted by a bi-phasic model, except for 3-OH-QA, where SFO fits were acceptable. The resulting $\mathrm{DT}_{50}$ and $\mathrm{DT}_{90}$ values are listed in Table 3 (Panel A).

Degradation of QE was extremely fast in soils MBS, $\mathrm{MR}$, and CS with $\mathrm{DT}_{50}$ values $<1$ day, but clearly slower in soil EB with a $\mathrm{DT}_{50}$ value of 21 days (Fig. 4, left). The bi-phasic degradation was most pronounced in soils $\mathrm{EB}$ and $\mathrm{CS}$ with high $\mathrm{DT}_{90}$ values of $>1000$ days and 68 days, respectively. Degradation of the three metabolites was consistently slower. The primary metabolite QA was degraded with a $\mathrm{DT}_{50}$ value of $\approx 100$ days in soils $\mathrm{EB}$ and MBS. In CS, the $\mathrm{DT}_{50}$ value was $\approx 1$ year, and in MR, no degradation was observed (Fig. 4, second panel). Degradation curves of the secondary metabolite 3-OHQA were qualitatively similar to QA, but half-lives were 2-3 $\times$ lower (35-630 days, Fig. 4, third panel). Finally, the tertiary metabolite $3-\mathrm{OH}-\mathrm{CQO}$ was degraded with
$\mathrm{DT}_{50}$ values of 24-474 days. In comparison to the other metabolites, a slower degradation was observed in soil EB (Fig. 4, right).

As for 2,4-D and its metabolites, no clear correlation could be identified between soil parameters and rate of degradation. Degradation of all QE metabolites was slowest in soil MR (Fig. 4). Degradation of the parent compound itself was fastest in this soil, likely because of abiotic hydrolysis of QE to QA. Note that the water content was highest in soil MR. The geometric means listed in Table 3 (Panel A) were again calculated from normalized $\mathrm{DT}_{50}$ values, considering only the slow phase in case of bi-phasic kinetics (modeling endpoints). These $\mathrm{DT}_{50}$ values were $4-12 \times$ higher than those reported for agricultural soils [17].

\section{Formation of quizalofop-P-ethyl metabolites}

Quizalofop-P-ethyl is a so-called pro-herbicide, which is, due to its lipophilicity, more readily taken up through the cuticle of leaves. As with other "FOP" herbicides [23], the compound is rapidly transformed in plants to the corresponding acid, which is the herbicidally active substance.

In the railway soils, quizalofop-P-ethyl was also quantitatively transformed to quizalofop-acid (Fig. 5, left). However, the secondary and tertiary metabolites, 3-OH$\mathrm{QA}$ and 3-OH-CQO, were formed in much lower quantities ( $\leq 1 \%$, shown for soil EB in Fig. 5, second panel), also in experiments with QA (third panel). Only in experiments with incubation of 3-OH-QA, 3-OH-CQO reached amounts of up to $29 \%$ after 4 months (Fig. 5 , right).

Sequential fitting confirmed the quantitative transformation of QE to QA (formation fractions, 98-100\%). For the subsequent transformation of QA to 3-OH-QA, formation fractions of $0.5 \%$ and $3.0 \%$ were determined in soil EB and MBS, respectively (Table 3, Panel B). For the transformation of $3-\mathrm{OH}-\mathrm{QA}$ to $3-\mathrm{OH}-\mathrm{CQO}$, no

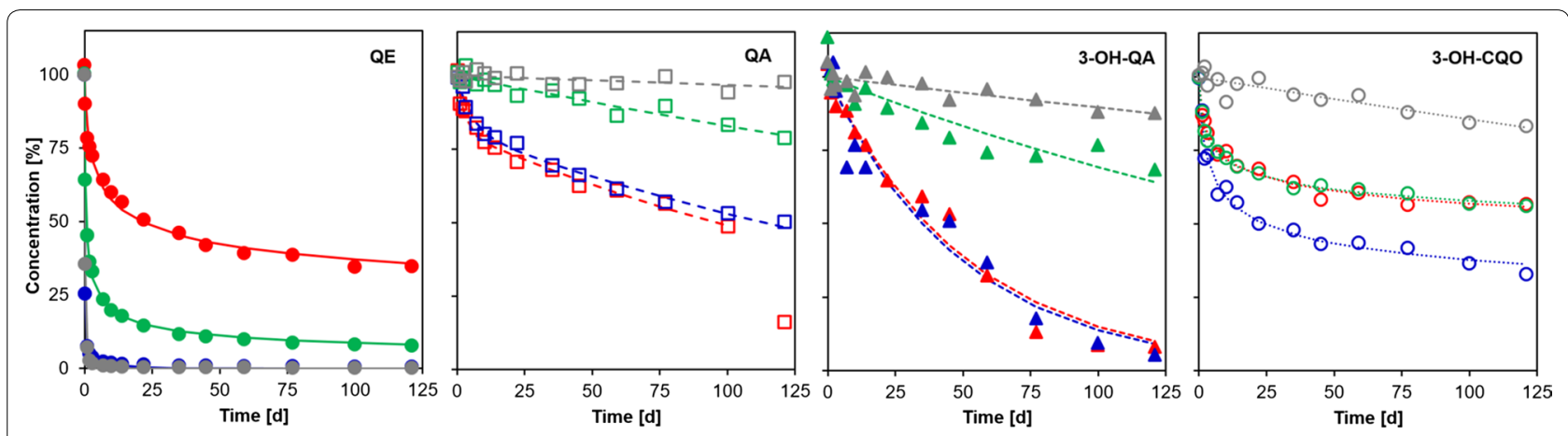

Fig. 4 Degradation of QE, QA, 3-OH-QA, and 3-OH-CQO in soils from railway tracks and a crushed sand. EB: red, MBS: blue, MR: grey, CS: green. Symbols show measured concentrations, lines are kinetic fits 

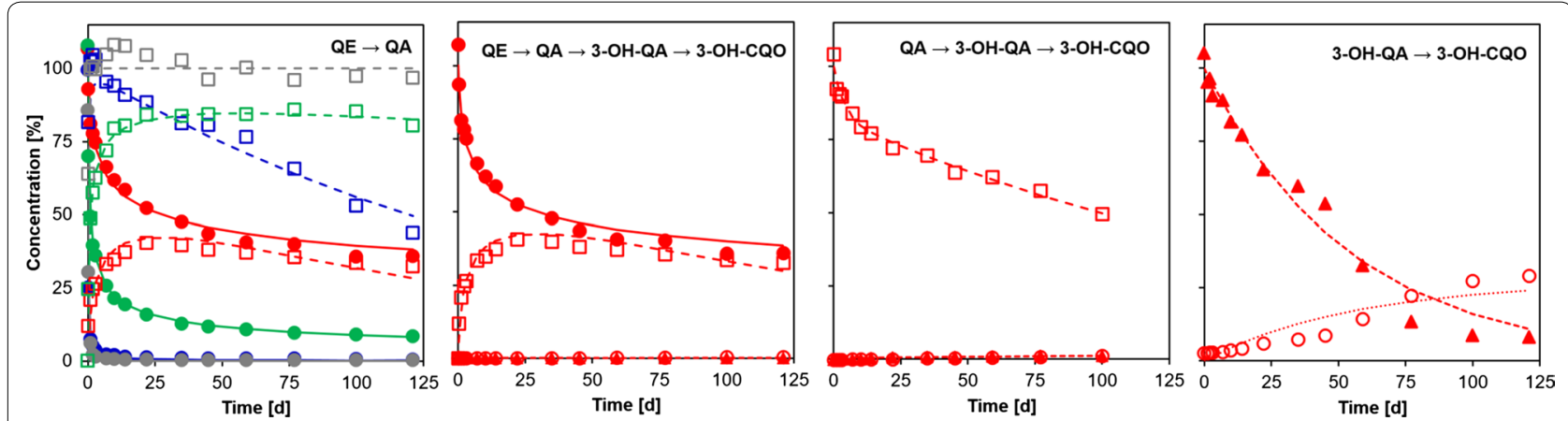

Fig. 5 Sequential degradation of QE to QA, 3-OH-QA, and 3-OH-CQO. Left: QE to QA in soil EB (red), MBS (blue), MR (grey), CS (green). Second: QE to QA, 3-OH-QA, and 3-OH-CQO in EB. Third: QA to 3-OH-QA and 3-OH-CQO in EB. Right: 3-OH-QA to 3-OH-CQO in EB. Symbols show measured concentrations, lines are kinetic fits

statistically significant formation fraction could be determined, but in soil EB, it must have been $>29 \%$ (maximum formation at the end of incubation).

In degradation studies with agricultural soils, formation fractions of $70-100 \%, 32-76 \%$, and $100 \%$, respectively, were determined for the reaction sequence $\mathrm{QE} \rightarrow \mathrm{QA} \rightarrow 3-\mathrm{OH}-\mathrm{QA} \rightarrow 3-\mathrm{OH}-\mathrm{CQO}$ [17]. Hydroxylation of QA to 3-OH-QA thus seems to be clearly less important in railway soils than in agricultural soils.

\section{Adsorption to railway soils}

Adsorption experiments were evaluated with the Freundlich model [39]:

$$
c_{\mathrm{s}}=K_{\mathrm{F}} c_{\mathrm{W}}^{\frac{1}{n}},
$$

where $c_{\mathrm{w}}$ is the concentration in the aqueous phase and $\mathrm{c}_{\mathrm{s}}$ the concentration in soil. The Freundlich adsorption coefficients $\left(K_{\mathrm{F}}\right)$ and the Freundlich exponents $(1 / n)$ were determined from linear regressions of $\log c_{\mathrm{w}}$ vs $\log c_{\mathrm{s}}$. These so-called Freundlich isotherms for 2,4-D, QE, and their metabolites in the four railway soils are shown in Figs. 6 and 7 , and corresponding $K_{\mathrm{F}}$ and $1 / n$ values are listed in Tables 4 and 5.

The compounds exhibited strongest adsorption to the construction material from site EB and weakest adsorption to subsoil from MR, except for 3-OH-CQO, which showed strongest adsorption to subsoil MBS and weakest adsorption to the crushed sand (CS) (Figs. 6 and 7). Adsorption of QE $\left(K_{\mathrm{F}}, 1.5-66 \mathrm{~mL} / \mathrm{g}\right)$ was about two orders of magnitude stronger than adsorption of 2,4-D $\left(K_{\mathrm{F}}, 0.04-0.28 \mathrm{~mL} / \mathrm{g}\right)$, which may be assumed to be present as a carboxylate anion in the railway soils $\left(\mathrm{pK}_{\mathrm{a}}\right.$ value, 3.4) [13]. $K_{\mathrm{F}}$ values of the metabolites were in between those of the two parent compounds. The weakest adsorption of 2,4-D was found in soil MR, where the adsorbed fraction represented only $3-18 \%$, depending on the concentration level. In such cases, determination of the concentration in soil is less accurate, resulting in wider confidence intervals (Additional file 1: Tables S6 and S7). For a precise determination of $K_{\mathrm{F}}$ values, a higher fraction of adsorbed test compounds would have been desirable.
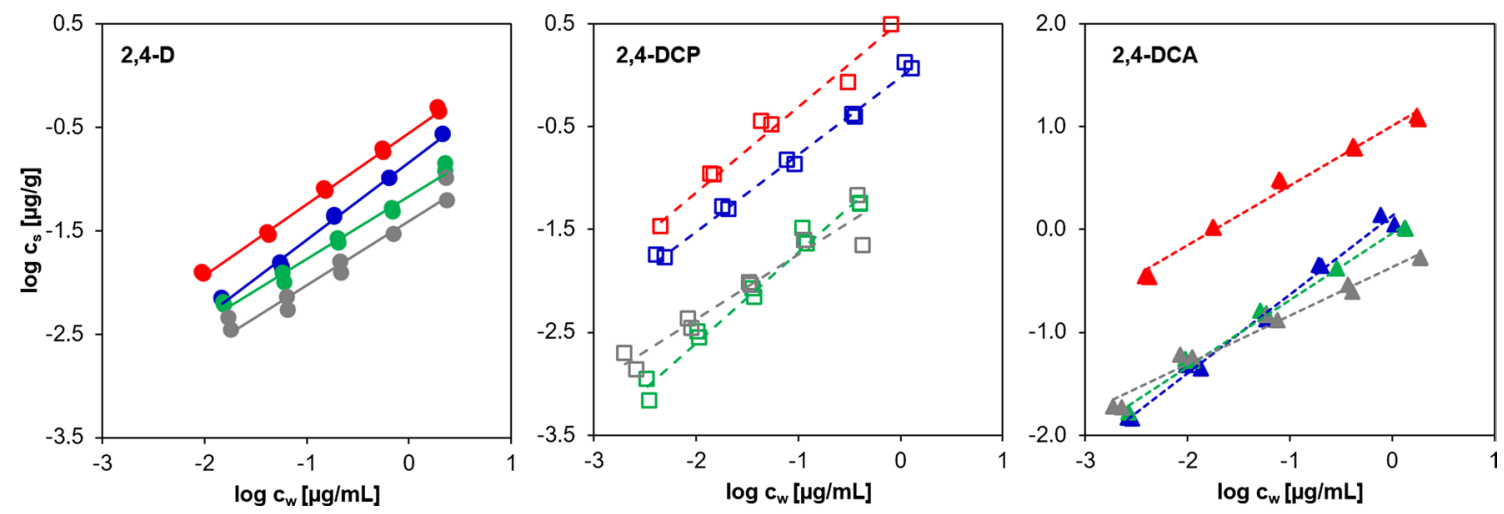

Fig. 6 Adsorption isotherms of 2,4-D, 2,4-DCP, and 2,4-DCA in soils from railway tracks and a crushed sand. EB: red, MBS: blue, MR: grey, CS: green. $C_{s}$ : amount adsorbed to soil, $C_{w}$ : concentration in solution. Note the different scales 

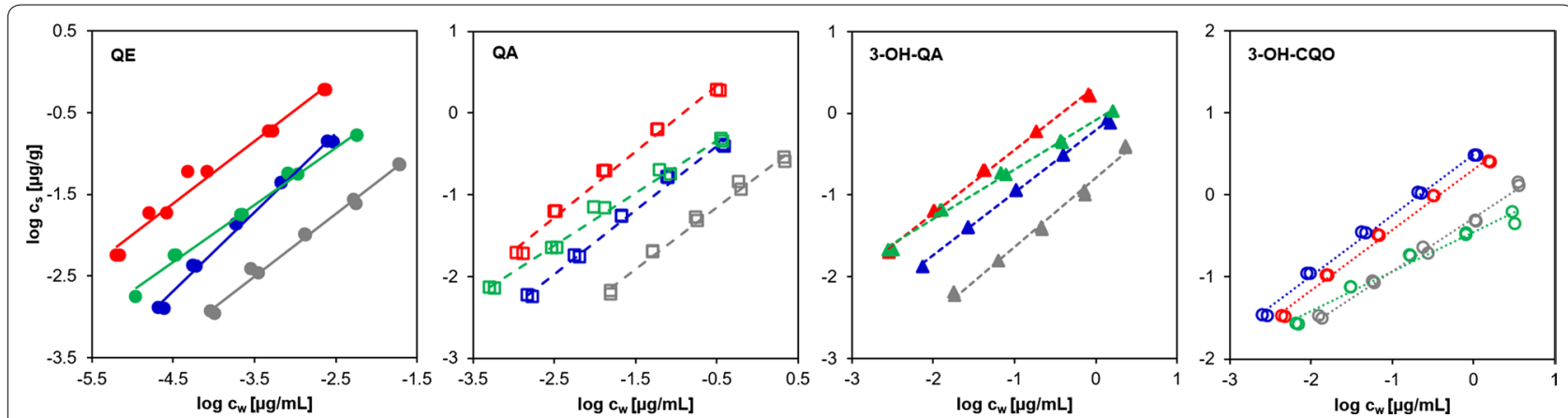

Fig. 7 Adsorption isotherms of QE, QA, 3-OH-QA, and 3-OH-CQO in soils from railway tracks and a crushed sand. EB: red, MBS: blue, MR: grey, CS: green. $c_{s}$ : amount adsorbed to soil, $c_{w}$ : concentration in solution. Note the different scales

Table 4 Freundlich adsorption coefficients $\left(K_{\mathrm{F}}\right)$ and exponents $(1 / \mathrm{n})$ of 2,4-D, 2,4-DCP, and 2,4-DCA

\begin{tabular}{|c|c|c|c|c|c|c|c|c|}
\hline & $\mathrm{pH}\left(\mathrm{CaCl}_{2}\right)$ & $C_{\text {org }}[\%]$ & $\begin{array}{l}K_{\mathrm{F}}[\mathrm{mL} / \mathrm{g}] \\
2,4-\mathrm{D}\end{array}$ & $1 / n$ & $\begin{array}{l}K_{\mathrm{F}}[\mathrm{mL} / \mathrm{g}] \\
2,4-\mathrm{DCP}\end{array}$ & $1 / n$ & $\begin{array}{l}K_{\mathrm{F}}[\mathrm{mL} / \mathrm{g}] \\
2,4-\mathrm{DCA}\end{array}$ & $1 / n$ \\
\hline \multicolumn{9}{|c|}{ Soils from railway tracks } \\
\hline EB & 7.7 & 0.15 & 0.28 & 0.69 & 3.32 & 0.83 & 10 & 0.58 \\
\hline MBS & 7.6 & 0.31 & 0.14 & 0.75 & 0.96 & 0.75 & 1.4 & 0.77 \\
\hline $\mathrm{MR}$ & 7.6 & $\approx 0.04$ & 0.04 & 0.62 & 0.08 & 0.63 & 0.43 & 0.47 \\
\hline CS & 7.5 & $<0.06$ & 0.07 & 0.61 & 0.14 & 0.88 & 0.93 & 0.65 \\
\hline Geom. mean & & $\approx 0.1$ & 0.10 & & 0.43 & & 1.5 & \\
\hline Arithm. mean & & & & 0.67 & & 0.77 & & 0.62 \\
\hline \multicolumn{9}{|c|}{ Agricultural soils [13] ${ }^{\mathrm{a}}$} \\
\hline Min-max & $5.0-7.5$ & $0.9-4.4$ & $0.19-0.83$ & $0.78-0.90$ & $3-25$ & $0.80-0.94$ & $10-27$ & $0.85-0.95$ \\
\hline Geom. mean & & 1.8 & 0.40 & & 8.3 & & 18 & \\
\hline Arithm. mean & & & & 0.83 & & 0.88 & & 0.92 \\
\hline
\end{tabular}

Confidence intervals are given in Additional file 1: Table S6

a Soils M800-M822 considered

Table 5 Freundlich adsorption coefficients $\left(K_{\mathrm{F}}\right)$ and exponents $(1 / n)$ of QE, QA, 3-OH-QA, and 3-OH-CQO

\begin{tabular}{|c|c|c|c|c|c|c|c|c|c|c|}
\hline & $\mathrm{pH}\left(\mathrm{CaCl}_{2}\right)$ & $C_{\text {org }}[\%]$ & $\begin{array}{l}K_{\mathrm{F}}[\mathrm{mL} / \mathrm{g}] \\
\mathrm{QE}\end{array}$ & $1 / n$ & $\begin{array}{l}K_{\mathrm{F}}[\mathrm{mL} / \mathrm{g}] \\
\mathrm{QA}\end{array}$ & $1 / n$ & $\begin{array}{l}K_{\mathrm{F}}[\mathrm{mL} / \mathrm{g}] \\
3-\mathrm{OH}-\mathrm{QA}\end{array}$ & $1 / n$ & $\begin{array}{l}K_{\mathrm{F}}[\mathrm{mL} / \mathrm{g}] \\
3-\mathrm{OH}-\mathrm{CQO}\end{array}$ & $1 / n$ \\
\hline \multicolumn{11}{|c|}{ Soils from railway tracks } \\
\hline EB & 7.7 & 0.15 & 66 & 0.76 & 5.4 & 0.81 & 2.1 & 0.78 & 2.0 & 0.74 \\
\hline MBS & 7.6 & 0.31 & 47 & 0.97 & 0.99 & 0.79 & 0.62 & 0.77 & 3.1 & 0.74 \\
\hline MR & 7.6 & $\approx 0.04$ & 1.5 & 0.77 & 0.17 & 0.76 & 0.16 & 0.84 & 0.52 & 0.65 \\
\hline CS & 7.5 & $<0.06$ & 6.5 & 0.70 & 0.96 & 0.64 & 0.83 & 0.60 & 0.35 & 0.48 \\
\hline Geom. mean & & $\approx 0.1$ & 13 & & 0.96 & & 0.65 & & 1.0 & \\
\hline $\begin{array}{l}\text { Arithm. } \\
\text { mean }\end{array}$ & & & & 0.80 & & 0.75 & & 0.75 & & 0.65 \\
\hline \multicolumn{11}{|c|}{ Agricultural soils [17] } \\
\hline Min-max & $4.3-8.1$ & $0.06-5.9$ & 15-99 & $0.83-0.88$ & $0.19-40$ & $0.69-0.89$ & $0.8-10$ & $0.80-1.07$ & $5.5-22$ & $0.59-0.80$ \\
\hline Geom. mean & & $2.3 / 1.0 / 2.0 / 2.0^{a}$ & 39 & & 5.2 & & 2.6 & & 9.9 & \\
\hline $\begin{array}{l}\text { Arithm. } \\
\text { mean }\end{array}$ & & & & 0.86 & & 0.81 & & 0.93 & & 0.66 \\
\hline
\end{tabular}

Confidence intervals are given in Additional file 1: Table S7

a In adsorption studies with QE/QA/3-OH-QA/3-OH-CQO 
Geometric mean organic carbon normalized adsorption coefficients $\left(K_{\mathrm{Foc}}\right)$ are currently used as input values for groundwater assessments in the context of registration in Europe [34]. In the pesticide leaching models, $K_{\text {Foc }}$ values are converted to $K_{\mathrm{F}}$ values based on the organic carbon content of the soils $\left(C_{\text {org }}\right)$ implemented in the leaching scenarios. The geomean $K_{\mathrm{F}}$ values obtained in our study on railway soils can be compared with typical values for agricultural soils (Tables 4 and 5). For this comparison, we only relied on studies accepted in the context of registration [13, 17]. Based on geomean $K_{\mathrm{F}}$, adsorption in the railway soils was clearly weaker than in agricultural soils, by a factor of 3-19.

Adsorption was non-linear for all compounds, with mean Freundlich exponents of $0.62-0.80$ (Tables 4 and $5)$, indicating weaker adsorption at higher concentrations. The mean $1 / n$ values were consistently lower in railway soils than in agricultural soils, i.e., non-linearity of adsorption was more pronounced.

\section{Estimation of adsorption and degradation in railway soils from data with agricultural soils}

Since adsorption and degradation data are usually not available for railway soils, the question may be posed whether such data can be estimated by extrapolation from agricultural soils. Sorption to organic matter is often considered as the predominant sorption mechanism for organic compounds in soils [40], i.e., it is assumed that $K_{\mathrm{F}}$ values are roughly proportional to the organic carbon content of soils $\left(C_{\mathrm{org}}\right) . K_{\mathrm{F}}$ values for railway soils $(r)$ may thus simply be estimated from $K_{\mathrm{F}}$ values for agricultural soils $(a)$, correcting for $C_{\text {org }}$ :

$$
K_{\mathrm{F}}(r)=K_{\mathrm{F}}(a) \frac{C_{\mathrm{org}}(r)}{C_{\mathrm{org}}(a)} .
$$

With this formula, we calculated $K_{\mathrm{F}}(r)$ values for the seven test substances in this study (2,4-D, QE, and their metabolites), based on the geometric means of $K_{\mathrm{F}}(a)$, $C_{\text {org }}(a)$, and $C_{\text {org }}(r)$ (Additional file 1: Tables S6 and S7). These estimates were generally lower $(1.5-7.6 \times)$ and thus more conservative than our measured adsorption coefficients, except for 2,4-DCP, where estimated and measured $K_{\mathrm{F}}$ values were almost equal. In the railway soils, sorption of the test substances (except 2,4-DCP) to mineral substrates may be important as well and the above formula does not account for their contribution to sorption.

Freundlich exponents $(1 / n)$ for agricultural soils were consistently higher than those determined in this study for railway soils (Tables 4 and 5), i.e., the use of $1 / n$ data from agricultural soils would also be more conservative regarding the prediction of leaching in soils. Overall, the estimation of sorption in railway soils from data with agricultural soils using the above approach seems to be conservative, in some cases very conservative. Sorption parameters measured specifically in railway soils may thus not be essential for a first tier groundwater assessment. However, it needs to be highlighted that this conclusion is based on only seven test substances.

Degradation half-lives in railway soils may be estimated in a similar way by extrapolation of data from agricultural soils, assuming that biological activity is linked to the organic matter content of a soil. This approach was, for example, implemented in the HardSPEC model, a simple tool developed in the UK for estimating surface water and groundwater exposure resulting from herbicides applied to hard surfaces [41]:

$$
\mathrm{DT}_{50}(r)=\mathrm{DT}_{50}(a) \frac{\mathrm{C}_{\text {org }}(a)}{\mathrm{C}_{\text {org }}(r)} .
$$

$\mathrm{DT}_{50}(r)$ values estimated with this formula (excluding 2,4-D) yielded $1.7-13 \times$ higher values than actually measured (Additional file 1: Tables S4 and S5), i.e., as for adsorption, this approach tends to be conservative as well. For 2,4-D, the estimated mean half-life was $\approx 2 \times$ lower, when considering only the initial slow phase of the degradation curves.

Concerning formation of metabolites, our experiments with railway soils showed substantial differences to agricultural soils. Generally, metabolites were formed in lower amounts. In particular, formation of the secondary and tertiary metabolite of QE (3-OH-QA and 3-OHCQO) seems to be unimportant in railway soils.

\section{Conclusions}

Groundwater protection is of particular importance when applying herbicides on railway tracks. The degradation and adsorption studies presented here allow a first assessment of the potential leaching of 2,4-D, quizalofop-P-ethyl, and their metabolites to groundwater. Based on these data, leaching is predicted to be highest for 2,4-D and quizalofop-acid. Degradation of these two compounds was considerably slower and the adsorption weaker in railway soils than in agricultural soils. For 2,4-DCP, it can be assumed that leaching is moderate. Its adsorption to railway soils was clearly weaker than in agricultural soils, but elimination was comparatively fast. Even less leaching is expected for 2,4-DCA. This metabolite was also formed in relatively low quantities of $\leq 2.6 \%$. Finally, negligible leaching is expected for quizalofop-P-ethyl. Its degradation was fast in railway soils and adsorption was relatively strong. For 3-OH-QA and 3-OH-CQO, a high inherent potential for leaching would 
be expected based on $\mathrm{DT}_{50}$ and $K_{\mathrm{F}}$ values, but their formation in railway soils was $\leq 1 \%$.

Based on degradability, mobility, and metabolite formation, a tentative qualitative ranking of the potential for groundwater contamination would be as follows: 2,4-D > QA > 2,4-DCP > 2,4-DCA > 3-OH-QA $\approx 3-\mathrm{OH}-$ $\mathrm{CQO}>\mathrm{QE}$. It is, however, uncertain, whether the observed increase of the degradation rate of 2,4-D in our laboratory experiments would also be found in the field. In addition to degradability, mobility, and metabolite formation, leaching is influenced by many other factors such as timing of application, application rates, soil properties, or weather conditions.

For an advanced groundwater exposure assessment, we consider computer simulations with pesticide leaching models or leaching studies under more realistic field conditions as a reasonable next step. A possible approach would be lysimeter studies, using coarse-textured soils with low organic carbon content from railway locations.

\section{Supplementary information}

Supplementary information accompanies this paper at https://doi. org/10.1186/s12302-020-00422-6.

Additional file 1. Details on analytical methods, soil adsorption experiments, volatilization experiments, and kinetic evaluation.

Additional file 2. All output files of the kinetic evaluation.

\section{Abbreviations}

2,4-D: 2,4-Dichlorophenoxyacetic acid; 2,4-DCA: 2,4-Dichloroanisole; 2,4-DCP: 2,4-Dichlorophenol; ACCase: Acetyl CoA Carboxylase; AMPA: Aminomethylphosphonic acid; $C_{\text {org }}$ : Organic carbon content; CS: Crushed sand; DFOP: Double first-order in parallel model; $\mathrm{DT}_{\mathrm{x}}$ : Time required for $\mathrm{x} \%$ dissipation; EB: Erlenbach; ECHA: European Chemicals Agency; EFSA: European Food Safety Authority; FOCUS: Forum for the coordination of pesticide fate models and their use; FOMC: First-order multi-compartment model; FOP: Aryloxyphenoxypropionate; GC: Gas chromatography; HardSPEC: Surface and ground water exposure model; HS: Hockey-stick model; $K_{F}$ : Freundlich adsorption coefficient; LC: Liquid chromatography; MBS: Münchenbuchsee; MR: Müntschemier; MS: Mass spectrometry; OECD: Organisation for Economic Co-operation and Development; PELMO: Pesticide leaching model; QA: Quizalofop-P-acid; QE: Quizalofop-P-ethyl; RMS: Rapporteur member state; SFO: Single first-order model.

\section{Acknowledgements}

We thank Nissan Chemical Industries (Tokyo, Japan) for two reference substances, M. Keller and R. Kasteel for helpful discussions regarding selection of the herbicides and performance of adsorption experiments, J. Bosshard for a thorough literature search, A. Bonvicini for determination of soil parameters, and J. Angst for support in the laboratory (all Agroscope). This project was funded by the Swiss Federal Office of Transport (FOT) and the Swiss Union of Public Transport, and their support is kindly acknowledged. In particular, we would like to thank S. Bellotto (FOT), G. Adolph (Swiss Federal Railways, SBB), P. Sydler (BLS railways), and L. Ballo (SOB railways).

\section{Authors' contributions}

$I B$ and TP designed the research project; $P P, I H$, and $A B$ conducted the degradation and sorption experiments and analyses; IB and TP performed the data analysis and were the major contributors in writing the manuscript. All authors read and approved the final manuscript.

\section{Funding}

This project was funded by the Swiss Federal Office of Transport (FOT) and the Swiss Union of Public Transport.

\section{Availability of data and materials}

The datasets supporting the conclusions of this article are included within the article and its additional files.

\section{Ethics approval and consent to participate}

Not applicable.

\section{Consent for publication}

Not applicable.

\section{Competing interests}

The authors declare that they have no competing interests.

Received: 24 July 2020 Accepted: 5 October 2020

Published online: 12 November 2020

\section{References}

1. Schweinsberg F, Abke W, Rieth K, Rohmann U, Zullei-Seibert N (1999) Herbicide use on railway tracks for safety reasons in Germany? Toxicol Lett 107:201-205

2. Torstensson L (2001) Use of herbicides on railway tracks in Sweden. Pesticide Outlook 16-21

3. Ramwell CT, Heather AIJ, Shepherd AJ (2004) Herbicide loss following application to a railway. Pest Manage Sci 60:556-564

4. Amaro-Blanco I, Osuna MD, Romano Y et al (2019) Selection for glyphosate resistance in Conyza spp. occurring in the railway network of southern Spain. Can J Plant Sci 99:413-419

5. Duke SO (2018) The history and current status of glyphosate. Pest Manage Sci 74:1027-1034

6. Vereecken $\mathrm{H}$ (2005) Mobility and leaching of glyphosate: a review. Pest Manage Sci 61:1139-1151

7. Albers CN, Jacobsen OS, Bester K, Jacobsen CS (2020) Leaching of herbicidal residues from gravel surfaces - a lysimeter-based study comparing gravels with agricultural topsoil. Environ Pollut 266:115225

8. Borggaard OK, Gimsing AL (2008) Fate of glyphosate in soil and the possibility of leaching to ground and surface waters: a review. Pest Manage Sci 64:441-456

9. James TK, Rahman A (2010) Chemical control of field horsetail (Equisetum arvense). N Z Plant Protect 63:102-107

10. European Food Safety Authority (2015) Conclusion on the peer review of the pesticide risk assessment of the active substance glyphosate. EFSA J 13(11):4302

11. International Agency for Research on Cancer (2017) Some Organophosphate Insecticides and Herbicides. IARC Monogr Eval Carcinog Risks Hum 112:321-412

12. European Chemicals Agency (2017) Glyphosate not classified as a carcinogen by ECHA. European Chemicals Agency, Helsinki

13. European Food Safety Authority (2014) Conclusion on the peer review of the pesticide risk assessment of the active substance 2,4-D. EFSA J 12(9):3812 ff

14. Hutto KC, Taylor JM, Byrd JDJ (2007) Evaluation of 2,4-D and 2,4-D Mixtures for Path Rush Control in Bermudagrass. Weed Technol 21:768-770

15. DiTomaso JM, Kyser GB (2013) Weed control in natural areas in the western United States. In. Weed Research and Information Center University of California, p 544

16. Hoyt PB, Carder AC (1962) Chemical control of field horsetail. Weeds 10(2):111-115

17. European Food Safety Authority (2009) Conclusion regarding the peer review of the pesticide risk assessment of the active substance quizalofop-P. EFSA J 7(7):1-216

18. Torstensson L, Cederlund H, Börjesson E, Stenström J (2002) Environmental problems with the use of diuron on Swedish railways. Pestic Outlook 13:108-111

19. Jacobsen CS, van der Keur P, Iversen BV et al (2008) Variation of MCPA, metribuzine, methyltriazine-amine and glyphosate degradation, sorption, 
mineralization and leaching in different soil horizons. Environ Pollut 156:794-802

20. Dollinger J, Dagès C, Voltz M (2015) Glyphosate sorption to soils and sediments predicted by pedotransfer functions. Environ Chem Lett 13:293-307

21. Paszko T, Muszynski P, Materska M, Bojanowska M, Kostecka M, Jackowska I (2016) Adsorption and degradation of phenoxyalkanoic acid herbicides in soils: a review. Environ Toxicol Chem 35(2):271-286

22. Vogel Al, Furniss BS (eds) (1989) Vogel's textbook of practical organic chemistry. Harlow Longman, London

23. Buerge IJ, Bächli A, Heller WE, Keller M, Poiger T (2015) Environmental behavior of the chiral herbicide Haloxyfop. 2. Unchanged enantiomer composition in Blackgrass (Alopecurus myosuroides) and Garden Cress (Lepidium sativum). J Agric Food Chem 63:2591-2596

24. Organisation for Economic Co-operation and Development (2000) OECD Guideline for the Testing of Chemicals, Section 1, Test No. 106: Adsorption-Desorption Using a Batch Equilibrium Method. Vol 106. OECD, p 45

25. Tessella Technology and Consulting (2016) CAKE, Computer Assisted Kinetic Evaluation. Syngenta Limited, Basel

26. FOCUS (Forum for the coordination of pesticide fate models and their use) (2014) Generic guidance for estimating persistence and degradation kinetics from environmental fate studies on pesticides in EU registration

27. Gustafson DI, Holden LR (1990) Nonlinear pesticide dissipation in soil: a new model based on spatial variability. Environ Sci Technol 24:1032-1038

28. Klein M (2002) The calculation of pesticide leaching close to railway tracks using PELMO. J Plant Dis Protect (XVIII): 405-412

29. Pfeffer M (1997) Untersuchungen zum Verlagerungsverhalten ausgewählter Herbizide in Gleiskörpern. Universität für Bodenkultur, Wien, p 101

30. Cederlund H, Börjesson E, Önneby K, Stenström J (2007) Metabolic and cometabolic degradation of herbicides in the fine material of railway ballast. Soil Biol Biochem 39(2):473-484

31. Anderson T-H, Domsch KH (1985) Maintenance carbon requirements of actively-metabolizing microbial populations under in situ conditions. Soil Biol Biochem 17(2):197-203
32. Organisation for Economic Co-operation and Development (2002) OECD Guideline for the Testing of Chemicals, Section 3, Test No. 307: Aerobic and Anaerobic Transformation in Soil. Vol 307. OECD, p 17

33. Buser H-R, Müller MD, Poiger T, Balmer ME (2002) Environmental behaviour of the chiral acetamide pesticide metalaxyl: enantioselective degradation and chiral stability in soil. Environ Sci Technol 36(2):221-226

34. FOCUS (FOrum for the Coordination of pesticide fate models and their USe) (2014) Generic Guidance for Tier 1 FOCUS Ground Water Assessments. Version 2.2. p 66

35. Buerge IJ, Müller MD, Poiger T (2013) The chiral herbicide beflubutamid (II): enantioselective degradation and enantiomerization in soil, and formation/degradation of chiral metabolites. Environ Sci Technol 47:6812-6818

36. European Food Safety Authority (2014) Conclusion on the peer review of the pesticide risk assessment of the active substance cyantraniliprole. EFSA Journal 12(9):3814ff

37. Reichert P (1994) AQUASIM — a tool for simulation and data-analysis of aquatic systems. Water Sci Technol 30:21-30

38. Poiger T, Müller MD, Buser H-R, Buerge IJ (2015) Environmental behavior of the chiral herbicide haloxyfop. 1. Rapid and preferential interconversion of the enantiomers in soil. J Agric Food Chem 63:2583-2590

39. Freundlich H (1907) Über die Adsorption in Lösungen. Z Phys Chem 57U(1):385-470

40. Wauchope RD, Yeh S, Linders JBHJ et al (2002) Pesticide soil sorption parameters: theory, measurement, uses, limitations and reliability. Pest Manage Sci 58:419-445

41. Hollis JM, Ramwell CT, Holman IP (2004) HardSPEC: a first-tier model for estimating surface- and ground-water exposure resulting from herbicides applied to hard surfaces. Cranfield University, Silsoe, Beds, p 79

\section{Publisher's Note}

Springer Nature remains neutral with regard to jurisdictional claims in published maps and institutional affiliations.

\section{Submit your manuscript to a SpringerOpen ${ }^{\circ}$ journal and benefit from:}

- Convenient online submission

- Rigorous peer review

- Open access: articles freely available online

- High visibility within the field

- Retaining the copyright to your article

Submit your next manuscript at $\boldsymbol{\nabla}$ springeropen.com 